\title{
Nasobiliary drainage
}

\author{
PAUL KORTAN, MD, FRCPC
}

\begin{abstract}
Placement of nasobiliary tubes has now become a widely accepted method for therapeutic drainage and instillation of solvents into the biliary tree. The author routinely uses a $300 \mathrm{~cm}$ long, 7 or 10 French, specially performed Teflon catheter, which adapts to the anatomy of the duodenum and bile ducts, for the following indications: decompression of obstructed bile duct in acute suppurative cholangitis; prevention of stone impaction after endoscopic sphincterotomy; sequential cholangiography; biliary fistula; instillation of solvents for common bile duct stones; local radiotherapy of biliary malignancies; aspiraticn of bile for chemical and bacteriological studies; and drainage of pancreatic pseudocysts. Pancreatic or biliary drains should supplement traditional diagnostic and therapeutic modalities in patients with surgical or medical lesions of the pancreas and biliary tree. Can J Gastroenterol 1990;4(9):588. 592
\end{abstract}

Key Words: Cholangitis, Dissolution, Endoscopic sphincterotomy, Nasobiliary tube

\section{Drainage naso-biliaire}

RESUME: La mise en place de tubes nasobiliaires est une méthode désormais largement acceptée permettant le drainage thérapeutique et l'instillation de solvants dans l'arbre biliaire. L'auteur utilise habituellement un cathéter Teflon préformé ( 7 ou 10 French) de $300 \mathrm{~cm}$, qui épouse la conformation anatomique du duodénum et des voies biliaires pour effectuer les interventions suivantes: décompression des voies biliaires obstruées dans l'angiocholite suppurée aiguë; prévention de l'enclavement des calculs après une sphinctérotomie endoscopique; cholangiographie séquentielle; fistule biliaire; instillation de solvants dans les calculs du cholédoque; radiothérapie locale des tumeurs biliaires malignes; aspiration de bile destinée aux examens chimiques et bactériologiques; et drainage des pseudokystes pancréatiques. $\mathrm{La}$ mise en place de drains pancréatiques ou biliaires devrait faire suite au diagnostic et aux modalités thérapeutiques traditionnels chez les patients souffrant de lésions chirurgicales ou médicales du pancréas et de l'arbre biliaire.

Division of Gastroenterology, University of Toronto, The Wellesley Hospital, Toronto, Ontario

Correspondence and reprints: Dr P Kortan, Division of Gastroenterology, Assistant

Professor, University of Toronto, The Wellesley Hospital, 160 Wellesley Street East, Suite 419 , Jones Building, Toronto, Ontario M4Y IJ3
P LACEMENT OF NASOBILIARY TUBES was first described by Wurbs and Classen in 1977 (1). Since that time the catheters have served as drainage tubes in cases of biliary strictures or common bile duct stones and for infusion of contrast material or agents that may dis. solve gallstones (Table 1). Over the past few years, many of these functions have been taken over by an indwelling biliary prosthesis.

\section{MATERIALS AND TECHNIQUE}

The most popular nasobiliary tube is a $300 \mathrm{~cm}$ long 7 or 10 French Teflon catheter with multiple openings along its distal end. This catheter is specially preformed according to the anatomy of the duodenum and bile duct, or has a distal pigtail to prevent dislocation

\section{TABLE 1}

Indications for nasobiliary drainage

Decompression of obstructed bile ducts in acute suppurative cholangitis Prevention of stone impaction after endoscopic sphincterotomy

Sequential cholangiography

Biliary fistula

Instillation of solvents for common bile duct stones

Sclerosing cholangitis

Local radiotherapy of biliary

malignancies

Aspiration of bile for chemical and bacteriological studies

Drainage of pancreatic pseudocyst 
from the biliary tree (Figure 1). The preformed part of the catheter is straightened with a guidewire before insertion into the instrumentation channel of the endoscope. The papilla is cannulated and the tip of the catheter introduced into the common bile duct and positioned above the stricture or alongside the common bile duct stones. In difficult cases it is the guidewire that is initially advanced above the level of the obstruction; the catheter is then advanced over the guidewire above the stricture. Once the catheter is in a good position, the guide-wire is carefully withdrawn into the endoscope, allowing the distal end of the catheter to take its preformed shape. Then, under fluoroscopic guidance the nasobiliary tube is advanced through the endoscope channel while the endoscope is carefully withdrawn. With the guidewire still in place, the duodenal and gastric loops of the drain can be adjusted. Once the position of the tube is ascertained by fluoroscopy, the guidewire is removed.

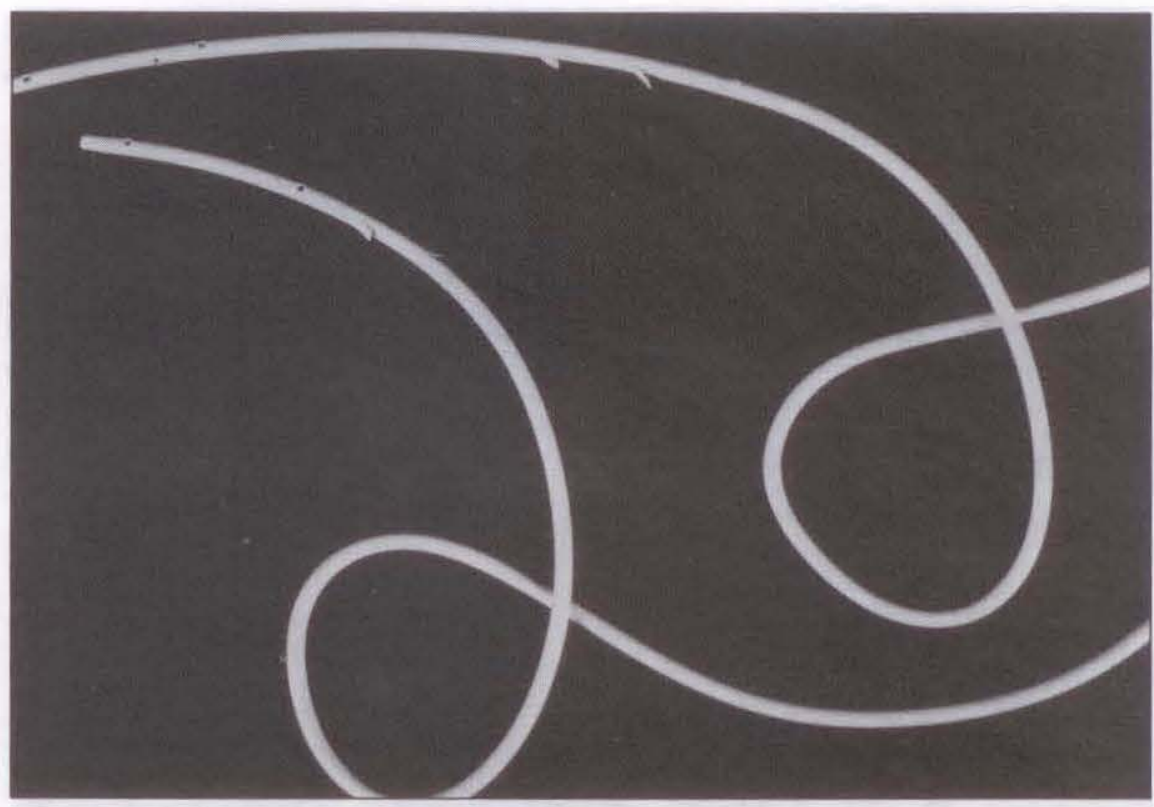

Figure 1) Nasobiliary tubes with duodenal loops

The next step is translocation of the biliary tube from the oropharynx to the nasal route (Figure 2). A lubricated 15 French polyethylene tube is inserted through a nostril and advanced to the oropharynx; it is then manually withdrawn through the mouth. The nasobiliary catheter is threaded through the lumen of the polyethylene tube which is then pulled back out of the nose,
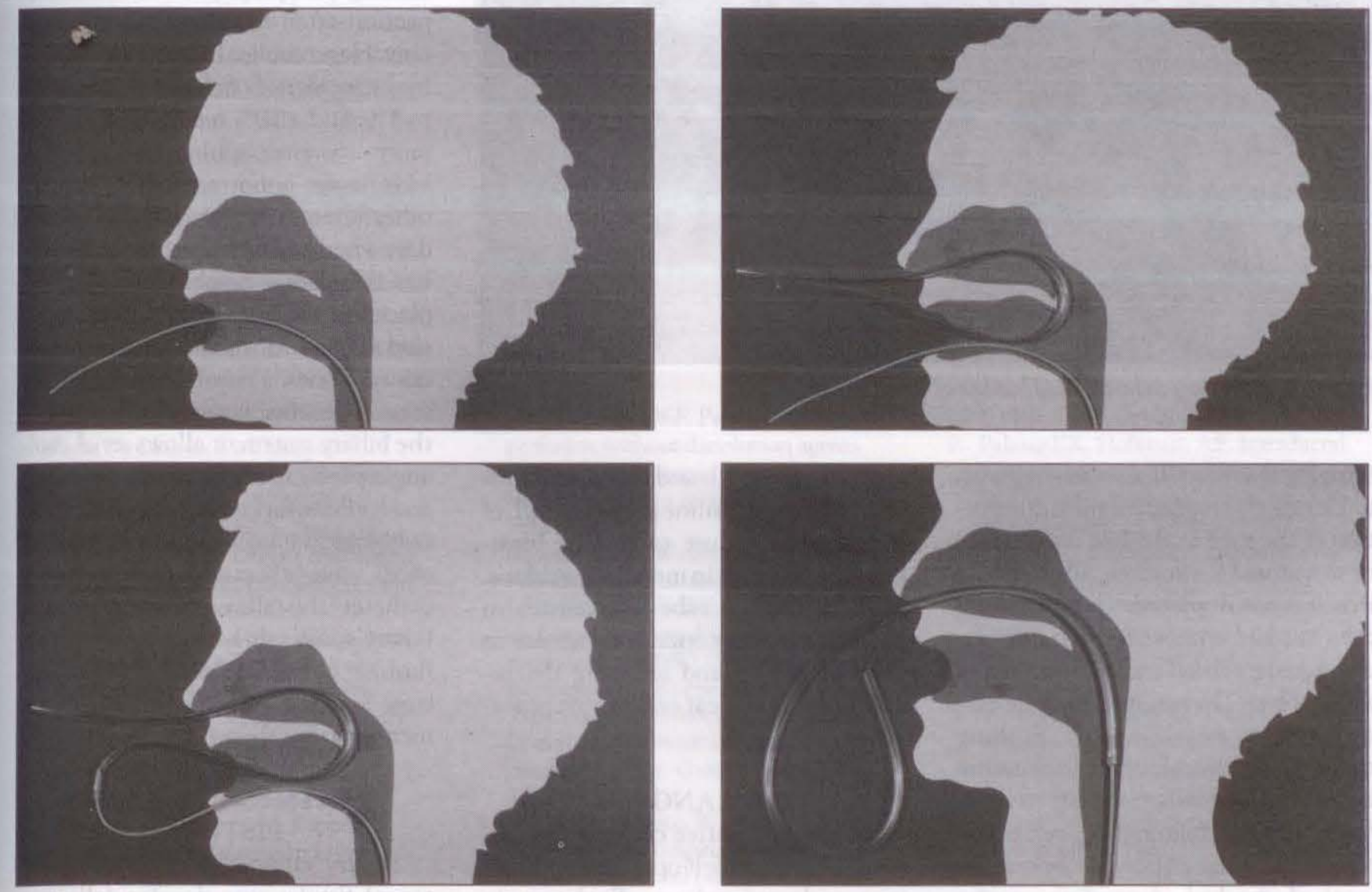

Figure 2) Translocation of nasobiliary catheter from oral to nasal route 


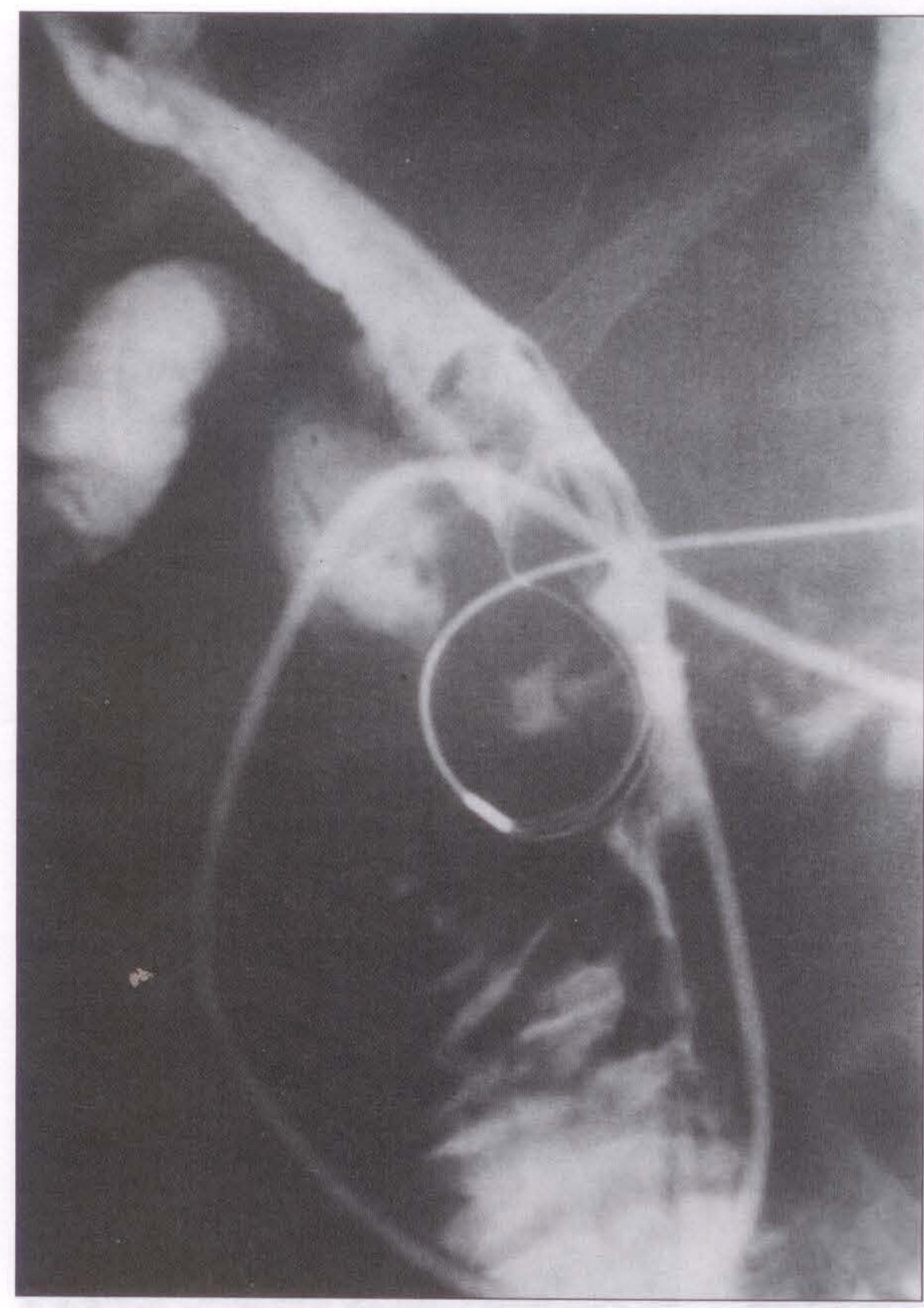

Figure 3) Nasobiliary catheter placed because of basket impaction

bringing the nasobiliary catheter with it. During this maneuvre the distal portion of the tube in the bile duct should be monitored fluoroscopically to assure that it is not displaced. The catheter is then secured with a tape fixed to the cheek and forehead and is connected to a plastic bag. The patency of nasobiliary catheters is maintained by flushing them with $10 \mathrm{~cm}^{3}$ of normal saline every $8 \mathrm{~h}$. The catheter is left to drain freely with the draining bag well below the waist of the patient or below the level of the bed, depending on the patient's position. The volume of bile is measured every $8 \mathrm{~h}$ and is replaced with one-half normal saline and $44 \mathrm{mEq} / \mathrm{L}$ of bicarbonate. Failure to replace bicarbonate may result in metabolic acidosis.

A nasobiliary tube can remain in place providing continuous access to the biliary tree and reducing the requirement for repeat endoscopic procedures.

\section{CHOLANGITIS}

Acute suppurative cholangitis is associated with a high operative morbidity and mortality. Endoscopic decompression by nasobiliary drainage is a safe method which reduces operative risk in extremely sick patients $(2,3)$. A nasobiliary tube may be placed in elderly patients with concomitant multisystem diseases who may have coagulopathy, and in whom sphincterotomy is not possible. Acute cholangitis may also be reversed with an in-dwelling biliary prosthesis, but if cholangitis persists, one cannot be certain whether the ongoing sepsis and jaundice are due to inadequate drainage or are secondary to an intrahepatic problem such as liver abscess. With the nasobiliary tube, on the other hand, one can be certain that adequate drainage has been achieved.

\section{PREVENTION OF STONE IMPACTION}

The most important risk factor for development of cholangitis after endo. scopic retrograde cholangiopancreatography (ERCP) for choledocholithiasis is failure to both clear the bile duct and establish adequate biliary drainage. Following the introduction of nasobiliary drainage for prophylaxis of stone impaction after endoscopic sphincterotomy, Hagenmuller (4) noted a decrease in the incidence of cholangitis from 3.3 to $1 \%$, and a $50 \%$ reduction in overall mortality after sphincterotomy. If a large stone is not removable but another attempt is planned after several days when edema from sphincterotomy has subsided, a nasobiliary catheter is placed in the bile duct for decompres. sion (Figure 3). In the presence of retained stones, a nasobiliary drain gives several benefits: it provides drainage of the biliary system; it allows serial cholangiography to check ductal clearance; and it allows for contact dissolution and radiological imaging for extracorporeal shock wave lithotripsy. The nasobiliary catheter also allows irrigation of the biliary system. It has been shown that flushing of the bile duct with $5 \%$ dextrose solution can remove stone frag. ments smaller than $1 \mathrm{~cm}$ diameter (5).

\section{TREATMENT OF BILIARY FISTULA}

Biliary cutaneous or biliary peritoneal fistulas may develop following injury to the bile duct during chole. 
cystectomy or after surgical exploration of the common bile duct and placement of a T-tube. If the tube is displaced and if there is obstruction of the distal common bile duct by a stone or stricture, a fistula will develop. The proper approach to treatment of such fistulas is ERCP to confirm the fistula and its location. If an obstructing stone is present in the distal common bile duct, sphincterotomy and stone removal are carried out and, after the obstruction has been relieved, either a biliary prosthesis or a nasobiliary tube should be placed to ensure closure of the fistula (6-8). Preferential flow of bile through a prosthesis or nasobiliary tube will allow healing of the fistulous tract.

\section{DISSOLUTION OF STONES}

If following sphincterotomy a large stone cannot be removed and mechanical lithotripsy is also unavailable, one may attempt to dissolve the stone. Mono-octanoin has been used for a number of years. The success rate with mono-octanoin dissolution is only 40 to $60 \%$, and some patients may experience significant side effects (9-11). It is usually necessary to perfuse the biliary system for four to seven days to produce dissolution. Recent studies have described dissolution of gallstones by perfusion of methyl tert-butyl ether (12). An important limitation of methyl tertbutyl ether is that it dissolves only cholesterol stones, and many common bile duct stones are of the calcium bilirubinate type. Infusion of EDTA has

\section{REFERENCES}

1. Wurbs D, Classen M. Transpapillary long standing tube for hepatobiliary drainage. Endoscopy 1977;9:192-3.

2. Leung JWC, Chung SCS, Sung JJY, Banez VP, Li AKC. Urgent endoscopic drainage for acute suppurative cholangitis. Lancet 1989;ii:1307-9.

3. Cairns SR, Dias I, Cotton PB, Salmon PR, Russel RCG. Additional endoscopic procedures instead of urgent surgery for retained common bile duct stones. Gut 1989;30:535-40.

4. Hagenmuller F, Classen M. Therapeutic endoscopic and percutaneous procedures. In: $\mathrm{Popper} \mathrm{H}$, Schaffner F, eds. Progress in Liver Diseases, Vol III. New York: Grune and Stratton, 1982:229-317.

5. Martin DF, McGregor JC, Lambert been reported as resulting in dissolution of these stones in $50 \%$ of patients (13).

\section{MANAGEMENT OF SCLEROSING CHOLANGITIS}

Many medical and surgical approaches to sclerosing cholangitis have been described, very few of which maintained remission or cure. Endoscopic intervention in sclerosing cholangitis has shown some early promising results $(14,15)$. Initially, dominant strictures may be dilated with balloons and followed by insertion of a nasobiliary catheter for perfusion of steroids, antibiotics and saline. Initial work in this area from Amsterdam suggested significant morphological and biochemical improvement in most parameters (14).

\section{IRIDIUM-192 IRRADIATION OF BILIARY TRACT MALIGNANCY}

Placement of a radioactive source using the afterloading technique is usually performed through a nasobiliary catheter $(16,17)$. The nasobiliary tube is inserted along with a large diameter biliary stent which allows biliary drainage during radiation. After the treatment has been completed, the nasobiliary tube is removed and the endoprosthesis left in place to allow for biliary drainage. The ability of intraluminal irradiation to improve palliation and survival in patients with malignant bile duct obstruction remains uncertain. Controlled studies are required.

ME, Tweedle DEF. Pernasal catheter perfusion without dissolution agents following endoscopic sphincterotomy for common duct stones. $\mathrm{Br}$ J Surg 1989;76:410-1.

6. Sauerbruch T, Weinzierl M, Holl J, Pratschke E. Treatment of nonhealing biliary-cutaneous fistulas by internal endoscopic biliary drainage. Gastroenterology 1986;90:1993-2003.

7. Burmeister W, Koppen MO, Wurbs D. Treatment of a biliocutaneous fistula by endoscopic insertion of a nasobiliary tube. Gastrointest Endosc 1985;31:279-81.

8. Siegel JH, Pullano W, Ramsey WH. Sclerosing cholangitis, benign bile duct strictures and biliary cutaneous/ peritoneal fistulas: Room at the top for endoscopic management. Gastrointest

\section{DIAGNOSTIC STUDIES}

From a diagnostic standpoint, nasobiliary and nasopancreatic tubes offer access to bile and pancreatic juice for culture and sensitivity, biochemical analysis and cytological examination. The last is particularly helpful in patients with ductal changes due to chronic pancreatitis in whom differentiation of benign from malignant disease by ERCP may be impossible. Positive cytology with transnasal drainage would eliminate the need for additional diagnostic testing.

\section{DRAINAGE OF PANCREATIC PSEUDOCYST}

Following endoscopic transduodenal or transgastric drainage of pancreatic pseudocysts, a nasocystic drainage tube can be used to assess the reduction in cavity size by injecting water-soluble contrast medium, and employed as a guide of the necessity of widening the cyst duodenostomy (18).

\section{SUMMARY}

The endoscopic insertion of biliary and pancreatic drains at the time of ERCP can provide access to bile and pancreatic ducts, decompress an obstructed biliary tree or pancreatic duct with a pseudocyst, and allow infusion of solvents. Pancreatic or biliary drains should supplement traditional diagnostic and therapeutic modalities in patients with surgical or medical lesions of the pancreas and biliary tree.

Endosc 1986;32:166. (Abst)

9. Palmer KR, Hofmann AF. Intraductal monooctanoin for the direct dissolution of bile duct stones: Experience in 343 patients. Gut 1986;27:196-202.

10. Thistle JL, Carlson GL, Hofmann AF, et al. Monooctanoin, a dissolution agent for retained cholesterol bile duct stones: Physical properties and clinical application. Gastroenterology 1980;78:1016-22.

11. Venu RP, Gennen JE, Toouli J, Hogan WD, Kozlov N, Stewart ET. Gallstone dissolution using monooctanoin infusion through an endoscopically placed nasobiliary catheter. Am ] Gastroenterol 1982;77:227-30.

12. Thistle JL, May GR, LeRoy AJ, et al. Dissolution of cholesterol gallbladder stone by methyl tert-butyl ethèr ad- 
ministered by percutaneous transhepatic catheter. N Engl J Med 1989;320:633-9.

13. Leuschner $\mathrm{U}$, Wurbs $\mathrm{D}$, Baumgartel $\mathrm{H}$, Helm EB. Alternating treatment of common bile duct stones with a modified glyceryl-1-monooctanoate preparation and a bile acid-EDTA solution by nasobiliary tube. Scand ] Gastroenterol 1981;16:497-503.

14. Grijm R, Huibregtse K, Bartelsman J, et al. Therapeutic problems in primary sclerosing cholangitis. Dig Dis Sci 1986;31:792-8.

15. Johnson GK, Geenen JE, Venu RP, Hogan WJ. Endoscopic treatment of biliary duct strictures in sclerosing cholangitis: Follow-up assessment of a new therapeutic approach.

Gastrointest Endosc 1987;33:9-12.

16. Venu RP, Geenen JE, Hogan WJ, Johnson GK, Klein K, Stone J. Intraluminal radiation therapy for biliary tract malignancy: An endoscopic ap- proach. Gastrointest Endosc 1987;33:236-8.

17. Levitt MD, Laurence BH, Cameron F, Klemp PF. Transpapillary iridium192 wire in the treatment of malignant bile duct obstruction. Gut 1988;29:149-52.

18. Kozarek RA, Brayko CM, Harlan J, Sanowski RA, Cintora I, Kovac A. Endoscopic drainage of pancreatic pseudocysts. Gastrointest Endosc 1985;31:322-8. 


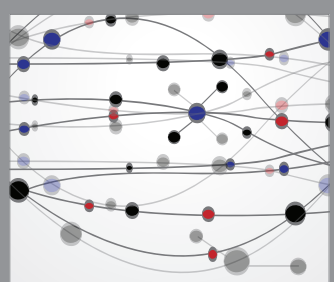

The Scientific World Journal
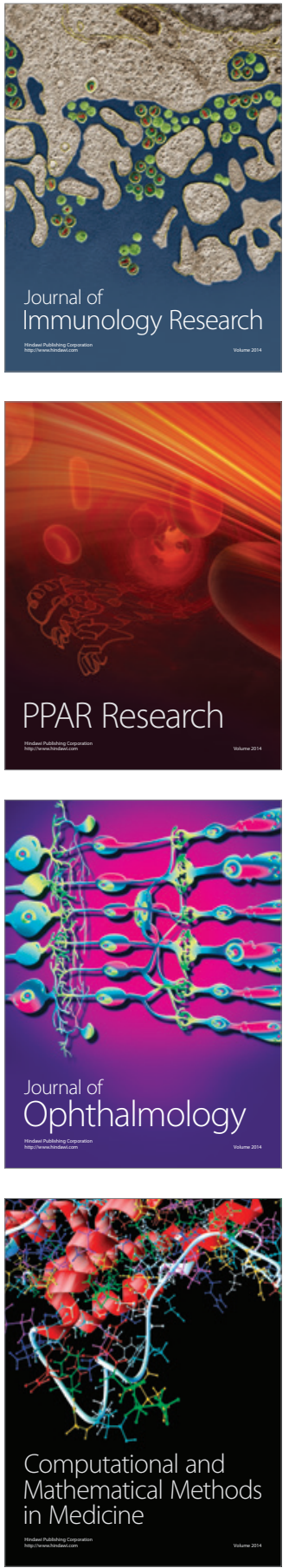

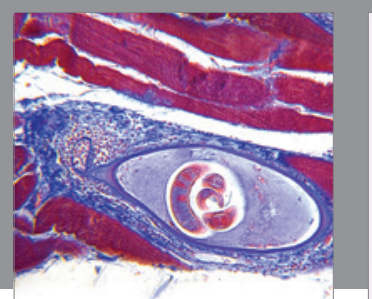

Gastroenterology Research and Practice

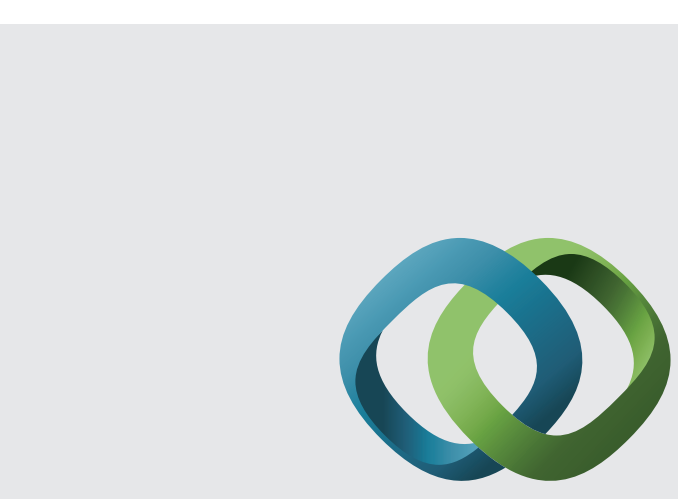

\section{Hindawi}

Submit your manuscripts at

http://www.hindawi.com
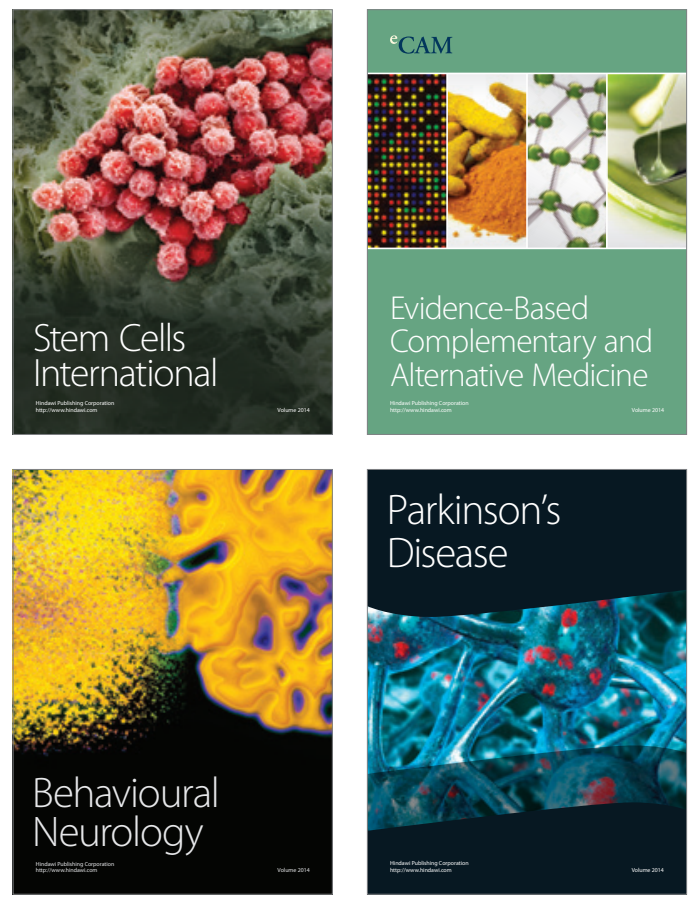
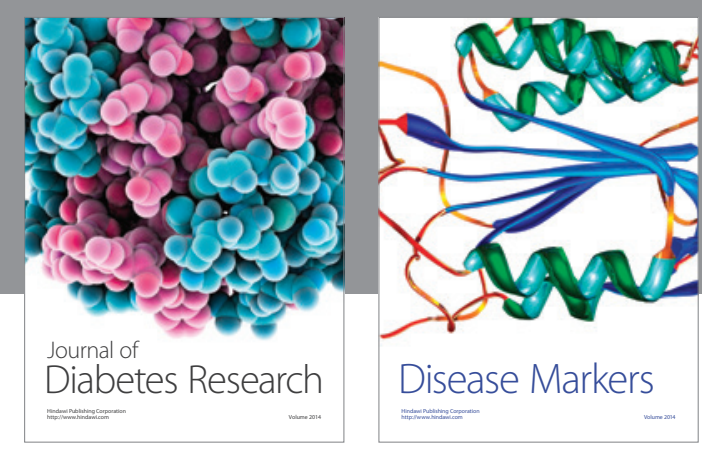

Disease Markers
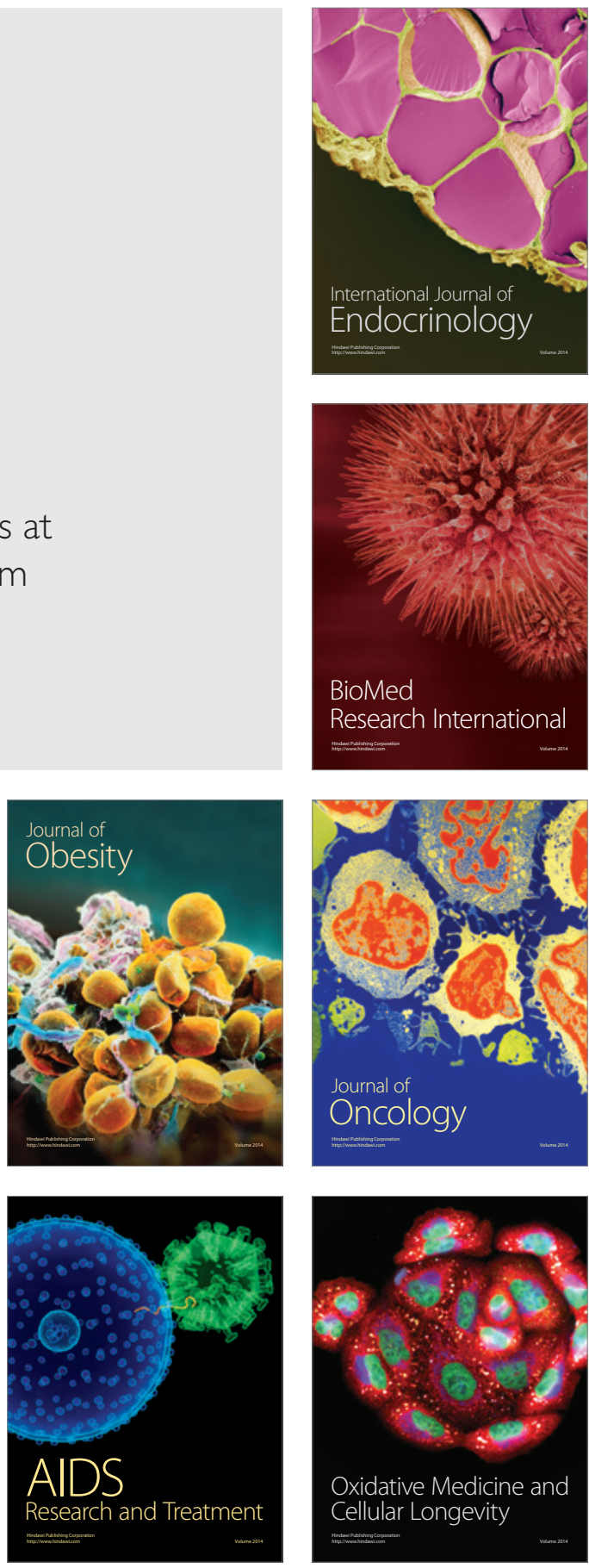